\title{
A Design of Wide Band and Wide Beam Cavity-Backed Slot Antenna Array with Slant Polarization
}

\author{
Huiying Qi, ${ }^{1,2}$ Ke Xiao, ${ }^{1}$ Fei Zhao, ${ }^{2}$ Shunlian Chai, ${ }^{1}$ and Wenlu Yin ${ }^{2}$ \\ ${ }^{1}$ College of Electronic Science and Engineering, National University of Defense Technology, Changsha, Hunan 410073, China \\ ${ }^{2}$ Southwest Electronics and Telecommunication Technology Research Institute, Chengdu, Sichuan 610041, China \\ Correspondence should be addressed to Huiying Qi; qiqhy@163.com
}

Received 11 June 2016; Accepted 29 September 2016

Academic Editor: Jaume Anguera

Copyright ( 2016 Huiying Qi et al. This is an open access article distributed under the Creative Commons Attribution License, which permits unrestricted use, distribution, and reproduction in any medium, provided the original work is properly cited.

\begin{abstract}
Design of antenna array under the limitation of restricted size is a challenging problem. Cavity-backed slot antenna is widely used because of its advantages of small size, wide band, and wide beam. In this paper, a design of wide band and wide beam cavity-backed slot antenna array with the slant polarization is proposed. To obtain wide band and wide beam with limited size, the inverted microstrip-fed cavity-backed slot antenna (IMF-CBSA) is adopted as the element of $1 \times 4$ antenna array. The slant polarized antennas and their feeding networks are adopted because of their simple structures. The performance of the proposed antenna array is verified by the simulations and experiments. The measured VSWR $<2$ bandwidth is $55 \%$ at the center frequency $21.8 \mathrm{GHz}$, and the gain is larger than $12.2 \mathrm{~dB}$. Experimental results demonstrate that the proposed design achieves wide band and beam with the size of $68 \mathrm{~mm} \times 56 \mathrm{~mm} \times 14.5 \mathrm{~mm}$.
\end{abstract}

\section{Introduction}

Slot antennas have advantages of low-profile, light weight, and ease of integration $[1,2]$. The cavity-backed slot antenna (CBSA), where the slot is backed with rectangular cavity, achieves unidirectional radiation [3-5]. The CBSA can be fed by probe [5], metal waveguide, substrate integrated waveguide (SIW) [6], and microstrip [7, 8]. With the use of printed circuit board, the structure of the SIW and microstrip is simpler than the probe and metal waveguide. The size of microstrip is smaller than the SIW. Therefore, the microstripfed CBSA (MF-CBSA) has simple structure and small size.

The bandwidth of the MF-CBSA element depends on the parameters of the slot. By the slot design, the slot antennas can have wider band than patch antennas. In general, the wide-slot MF-CBSA has larger bandwidth than the narrowslot MF-CBSA $[9,10]$. For example, the bandwidth of the MFCBSA in [10] achieves up to $35 \%$. The inverted microstripfed CBSA (IMF-CBSA) has better performance on the gain and bandwidth than the MF-CBSA [11]. For example, the bandwidth of the IMF-CBSA in [11] is 43\% which is larger than that of the MF-CBSA in [10].
Though the IMF-CBSA element has wide beam, the beam widths of the IMF-CBSA arrays in $[11,12]$ are not enough large because they are plane arrays. To obtain the wide beam array, the element should have wide beam and the array should be a linear array. The purpose of this study is to design an antenna array with the wide band, wide beam, high gain, and slant polarization.

Though the IMF-CBSA arrays in $[11,12]$ obtain wide band and high gain, the polarization is horizontal polarization and circular polarization, respectively. The slant polarized and circular polarized antennas can receive both vertical and horizontally polarized waves. The slant polarized antennas and their feeding networks are simpler than those circular polarized antennas [13]. The slant polarization can be obtained by two methods: the simultaneously excited horizontal and vertical polarized element or rotating horizontal or vertical polarized element [14-17]. The antenna and feeding network designed by the second method are simpler than those of the first method.

In this paper, a design of wide band and wide beam cavity-backed slot antenna array with the slant polarization is proposed. To obtain wide band and wide beam with limited 


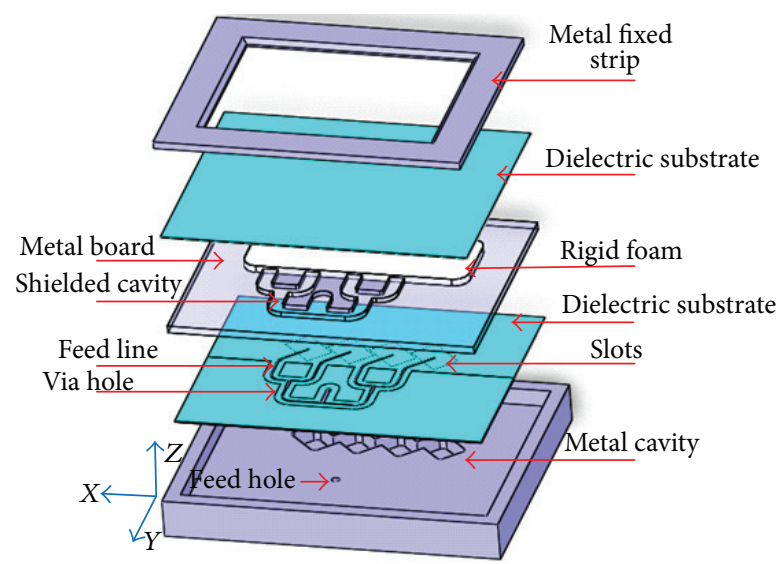

FIGURE 1: 3D structure model of IMF-CBSA array.

size, the inverted microstrip-fed cavity-backed slot antenna (IMF-CBSA) is adopted as the element of $1 \times 4$ antenna array. The $45^{\circ}$ slant polarization is achieved by slanting the IMF-CBSA. The good performance of the proposed antenna array is verified by the simulations and experiments. The measured VSWR $<2$ bandwidth is $55 \%$ at the center frequency $21.8 \mathrm{GHz}$, and the gain is larger than $12.2 \mathrm{~dB}$.

\section{Structure of Slant Polarized IMF-CBSA Array}

2.1. Structure of IMF-CBSA Array with Feeding Network. The structure design of the IMF-CBSA array with the feeding network is illustrated in Figure 1. The metal strips are added to fix the structure. The feeding network is designed and added. The exciting port of the array is a coaxial probe. Through a converting structure from the coaxial probe to the shielded microstrip line, the electromagnetic wave is transmitted to the shielded microstrip line. A 1-4 power divided network based on the shielded microstrip line is designed to feed four antenna elements with the equal amplitude and phase. The whole size of the array structure is $68 \mathrm{~mm} \times 56 \mathrm{~mm} \times$ $14.5 \mathrm{~mm}$.

Figure 2 shows a block diagram of the feeding network configurations. As shown in Figure 3, the coaxial probe and the 1-4 power divider based on the shielded microstrip line are regarded as Region I. Region II is the converter from the shielded microstrip line to the microstrip line.

2.2. Slant Polarized IMF-CBSA Element Design. The configuration of the slant polarized IMF-CBSA element is shown in Figure 4 . From the top to the bottom, there are four layers including a dielectric substrate covered on the top layer, a rigid foam layer, a dielectric substrate with a feeding line on the upper surface and a slot on the lower surface, and a back cavity on the bottom layer. The dielectric substrate is Rogers 5880 with the relative permittivity $\varepsilon_{r}=2.2$ and the thickness
TABLE 1: Geometrical parameters of the slant polarized IMF-CBSA element.

\begin{tabular}{|c|c|c|}
\hline Symbol & $\begin{array}{l}\text { Value } \\
(\mathrm{mm})\end{array}$ & Description \\
\hline$l_{s}$ & 8.4 & Slot length \\
\hline$w_{s}$ & 5.6 & Slot width \\
\hline$l_{c}$ & 9.0 & Cavity length \\
\hline$w_{c}$ & 6.2 & Cavity width \\
\hline$h_{c}$ & 3.4 & Cavity depth \\
\hline$t$ & 0.254 & Dielectric substrate thickness \\
\hline$h_{p}$ & 1.5 & Rigid foam thickness \\
\hline$s$ & 4.8 & $\begin{array}{l}\text { Distance from the feeding line to } \\
\text { the cavity short edge }\end{array}$ \\
\hline$l_{m}$ & 2.95 & $\begin{array}{l}\text { Feed line extension from the } \\
\text { cavity long edge }\end{array}$ \\
\hline$w_{m}$ & 0.3 & Width of the microstrip line \\
\hline
\end{tabular}

$0.254 \mathrm{~mm}$. The coordinate system is also shown in Figure 4. As shown in Figure 1, the antenna is rotated to have $45^{\circ}$ slant polarization. The detailed geometrical parameters of the slant polarized IMF-CBSA element are listed in Table 1. These parameters are determined through the optimization process of simulations.

The slant polarized IMF-CBSA is simulated to verify the performances. The voltage standing wave ratio (VSWR) of the antenna is shown in Figure 5(a), where the bandwidth of VSWR $<2$ at the center frequency $23.45 \mathrm{GHz}$ is about $61 \%$. The radiation pattern at $22 \mathrm{GHz}$ is shown in Figure 5(b). The maximum gain is $5.6 \mathrm{~dB}$. At the $X O Z$-plane (i.e., $\varphi=0^{\circ}$ plane) and $Y O Z$-plane (i.e., $\varphi=90^{\circ}$ plane), the $3 \mathrm{~dB}$ beam width is $91^{\circ}$ and $97^{\circ}$, respectively. The maximum radiation direction is not perfectly perpendicular to the plane of the antenna (XOY-plane). This is because the feeding line is unsymmetrical along the long side and wide side direction of the slot. By adjusting the location of the feeding line, well radiation pattern direction is achieved. 


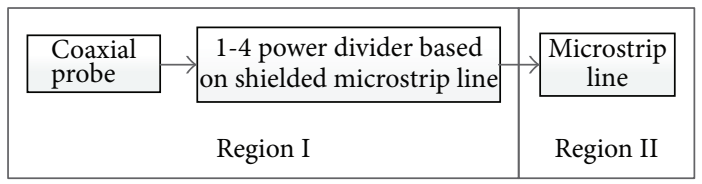

FIGURE 2: Block diagram of the feeding network configurations.

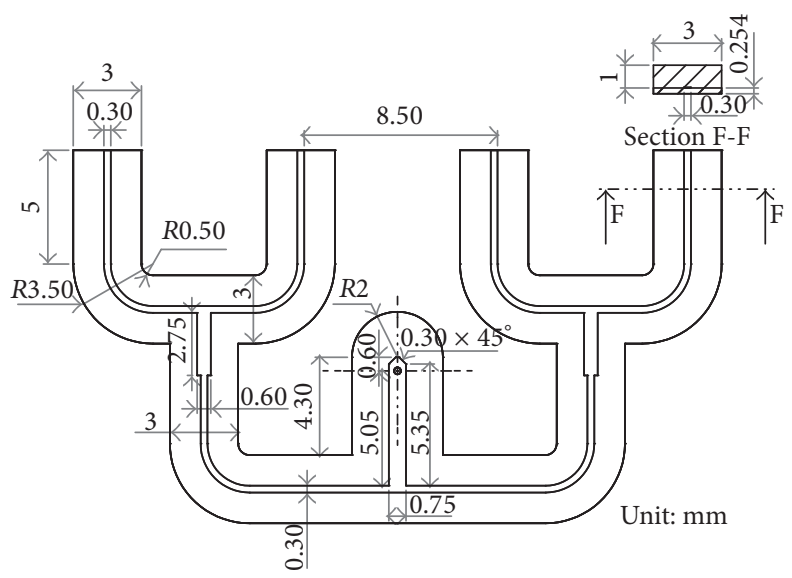

FIGURE 3: Structures of Region I in the feeding network.

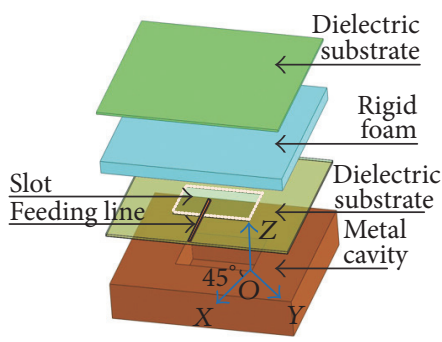

(a)

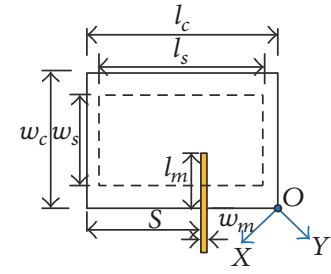

(b)

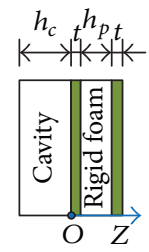

(c)

Figure 4: Configuration of the slant polarized IMF-CBSA element. (a) 3D model; (b) top view; (c) side view.

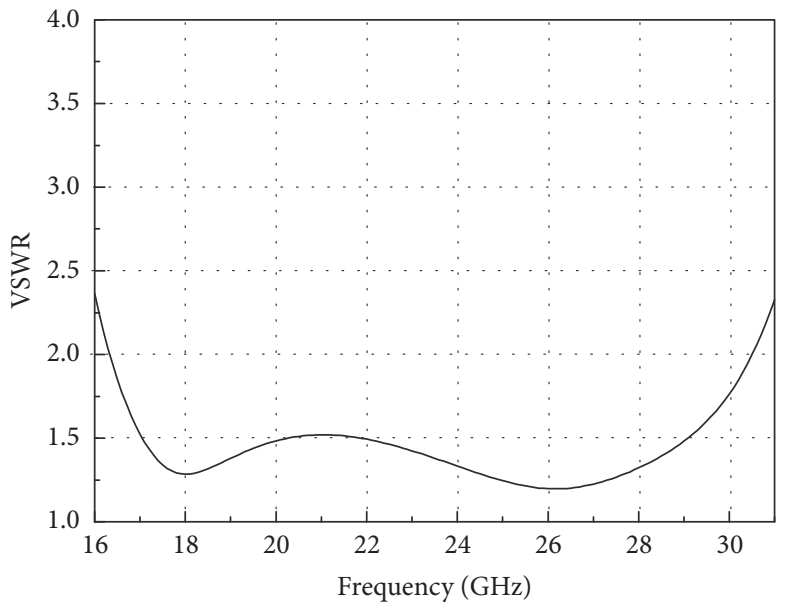

(a)

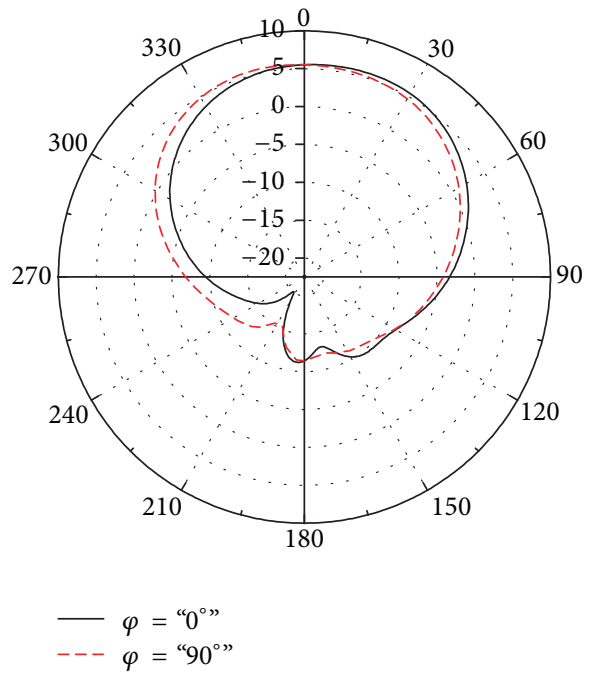

(b)

FIGURE 5: (a) VSWR of slant polarized IMF-CBSA element obtained in the simulation; (b) radiation pattern of slant polarized IMF-CBSA element obtained in the simulation. 


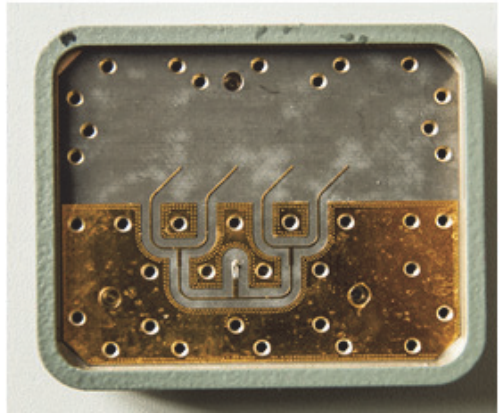

(a)

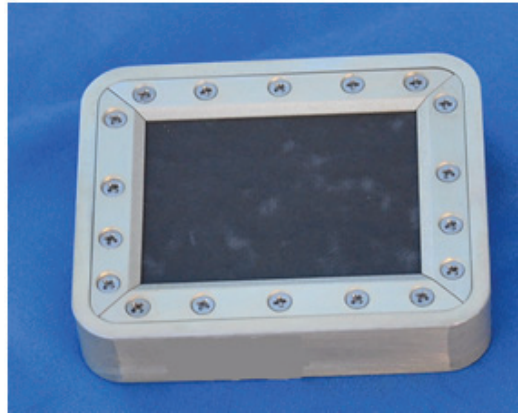

(b)

Figure 6: Photograph of the fabricated IMF-CBSA array. (a) The unassembled product; (b) the final product.

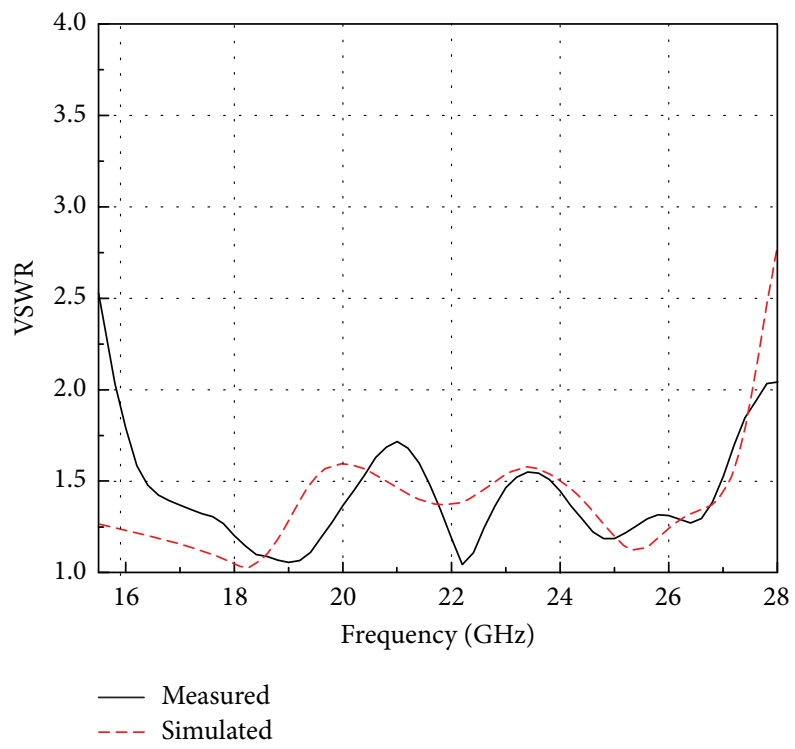

FIGURE 7: Simulated and measured VSWR of IMF-CBSA array.

\section{Experimental Results and Discussions}

The photograph of fabricated IMF-CBSA array is shown in Figure 6. Both the simulated and measured VSWR for the IMF-CBSA array are presented in Figure 7. For VSWR $<2$, the measured frequency ranges from $15.8 \mathrm{GHz}$ to $27.8 \mathrm{GHz}$. Thus, the bandwidth of IMF-CBSA array is about $12 \mathrm{GHz}$, and the relative bandwidth is $55 \%$ at the center frequency $21.8 \mathrm{GHz}$. From Figure 7, we can observe that the simulated and measured performance achieves good coherence. However there is a little difference at $15.5 \mathrm{GHz}$ and $28 \mathrm{GHz}$. This is because the simulation model does not have fixed screws and the via holes of shield microstrip line on the PCB adopt metal wall to reduce calculated amount.

Figure 8 shows the simulated and measured radiation patterns in $X Z$-plane and $Y Z$-plane at $18 \mathrm{GHz}, 22 \mathrm{GHz}$, and $26 \mathrm{GHz}$. From Figure 8, we can observe that the measured radiation patterns show good coherence with the simulated radiation pattern. The measured values of the beam width and the gain are listed in Table 2. At YZ-plane, the radiation pattern has wide beam which is larger than $59.1^{\circ}$.
TABLE 2: Measured beam width and gain of IMF-CBSA array.

\begin{tabular}{lcccc}
\hline \multirow{2}{*}{ Frequency $(\mathrm{GHz})$} & \multicolumn{2}{c}{ Beam width $\left(^{\circ}\right)$} & \multicolumn{2}{c}{ Gain $(\mathrm{dB})$} \\
& $\varphi=0^{\circ}$ & $\varphi=90^{\circ}$ & $\varphi=0^{\circ}$ & $\varphi=90^{\circ}$ \\
\hline 18 & 24.3 & 59.1 & 12.20 & 9.98 \\
22 & 21.3 & 84.3 & 13.46 & 9.67 \\
26 & 18.3 & 84.3 & 13.11 & 10.37 \\
\hline
\end{tabular}

The maximum gain is more than $12.2 \mathrm{~dB}$ within the whole band. The radiation and aperture efficiencies are $86.8 \%$ and $91.8 \%$ at $22 \mathrm{GHz}$, respectively.

To analyze the performance of feeding network, the feeding network simulation is conducted and the corresponding VSWR performance is shown in Figure 9. For Region I shown in Figure 2, the frequency of VSWR $<2$ ranges from $15.5 \mathrm{GHz}$ to $28.5 \mathrm{GHz}$. For Region II shown in Figure 2, the VSWR value is below 1.07 in this whole band. From the results in Figure 9, we conclude that feeding network achieves good performance. 


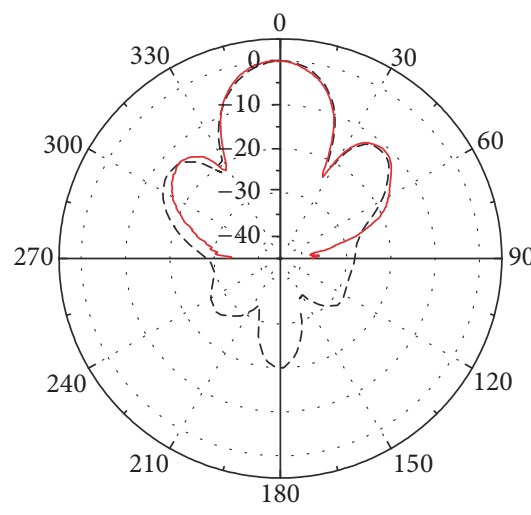

- - - Simulated

- Measured

(a)

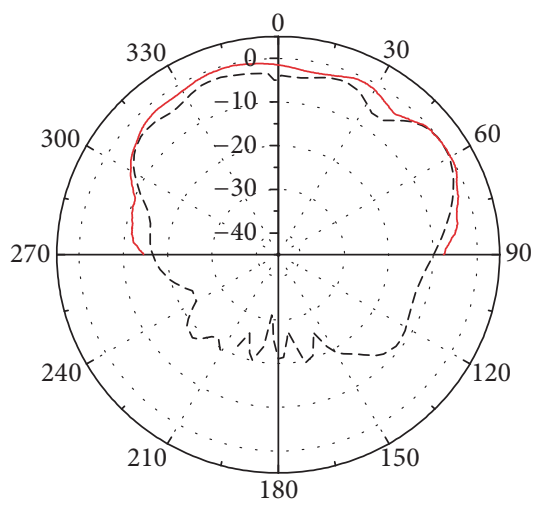

--- Simulated

— Measured

(d)

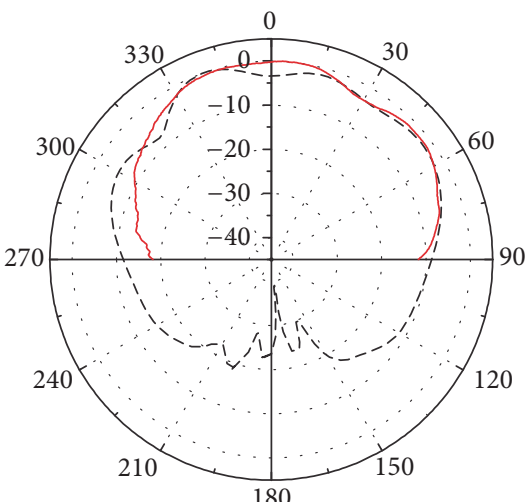

- - Simulated

- Measured

(b)

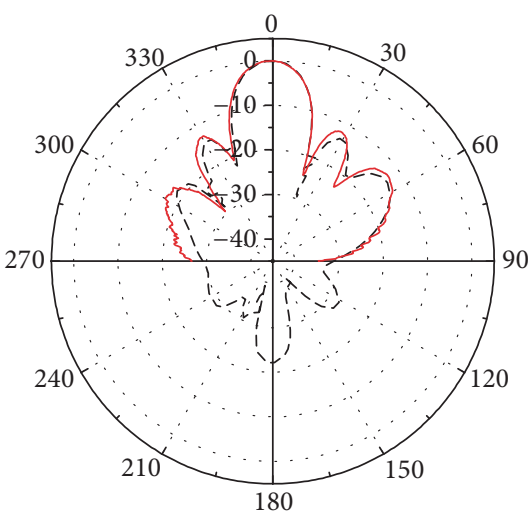

$\begin{aligned}--- & \text { Simulated } \\ - & \text { Measured }\end{aligned}$

(e)

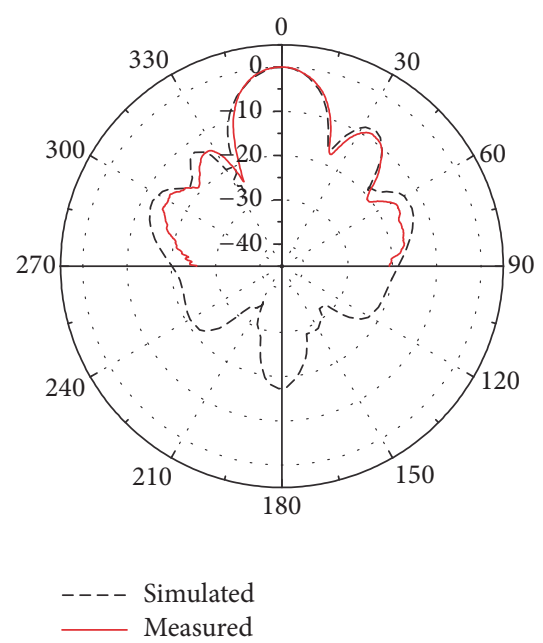

(c)

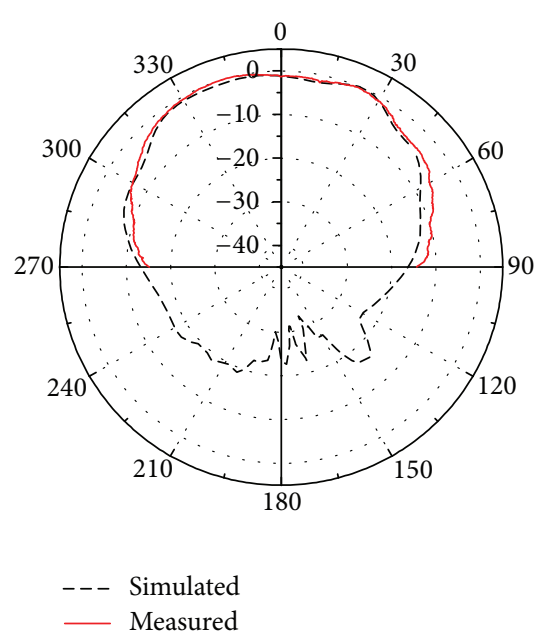

(f)

FIGURE 8: Simulated and measured radiation patterns of IMF-CBSA array in $X Z$-plane $\left(\varphi=0^{\circ}\right)$ and $Y Z$-plane $\left(\varphi=90^{\circ}\right):(a) 18 \mathrm{GHz}$ in $X Z$-plane; (b) $18 \mathrm{GHz}$ in $Y Z$-plane; (c) $22 \mathrm{GHz}$ in XZ-plane; (d) $22 \mathrm{GHz}$ in $Y Z$-plane; (e) $26 \mathrm{GHz}$ in XZ-plane; (f) $26 \mathrm{GHz}$ in $Y Z$-plane.

The simulated radiation pattern of the antenna array without the feeding network is also discussed. The configuration of the $1 \times 4$ IMF-CBSA array without feeding network is shown in Figure 10. In order to obtain the $45^{\circ}$ slant polarization, each antenna element has a $45^{\circ}$ rotation around the $z$-axis. To avoid producing grating lobe and reduce the mutual coupling, the distance $d_{e}$ between antenna elements is chosen to be $8.5 \mathrm{~mm}$ after the optimization process of simulation.

The simulated performance of the antenna array without the feeding network is shown in Figure 11 and Table 3. In the $\varphi=90^{\circ}$ plane within the whole band, the gain of the array achieves at least $10.6 \mathrm{~dB}$, and the $3 \mathrm{~dB}$ beam width of the array achieves at least $84.6^{\circ}$. The $S$-parameters of the IMF-CBSA array without feeding network are shown in Figure 12. The $S$ parameters of each port are less than $-20 \mathrm{~dB}$; thus the mutual coupling between the elements is acceptable.
TABLE 3: Beam width and gain of the IMF-CBSA array without feeding network obtained in the simulation.

\begin{tabular}{lcccc}
\hline \multirow{2}{*}{ Frequency $(\mathrm{GHz})$} & \multicolumn{2}{c}{ Beam width $\left(^{\circ}\right)$} & \multicolumn{2}{c}{ Gain $(\mathrm{dB})$} \\
& $\varphi=0^{\circ}$ & $\varphi=90^{\circ}$ & $\varphi=0^{\circ}$ & $\varphi=90^{\circ}$ \\
\hline 18 & 24.9 & 111.2 & 10.62 & 10.61 \\
20 & 22.9 & 109.7 & 10.90 & 10.96 \\
22 & 21.4 & 102.0 & 11.64 & 11.79 \\
24 & 19.5 & 94.1 & 12.52 & 12.55 \\
26 & 18.0 & 84.6 & 13.12 & 13.31 \\
\hline
\end{tabular}

\section{Conclusion}

A wide band and wide beam CBSA array with the slant polarization is proposed and investigated in this paper. The IMF-CBSA is chosen as the element of array to obtain the 


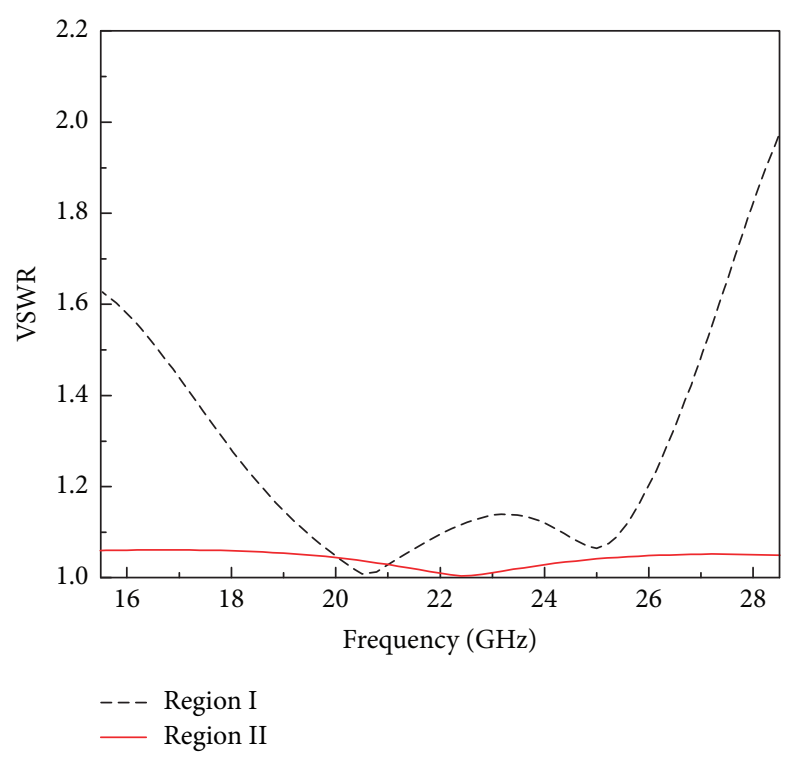

FIGURE 9: VSWR of feeding network in the simulation.

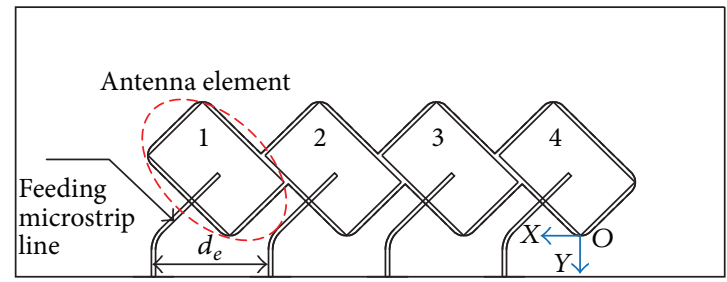

FIGURE 10: Configuration of the $1 \times 4$ IMF-CBSA array without feeding network.

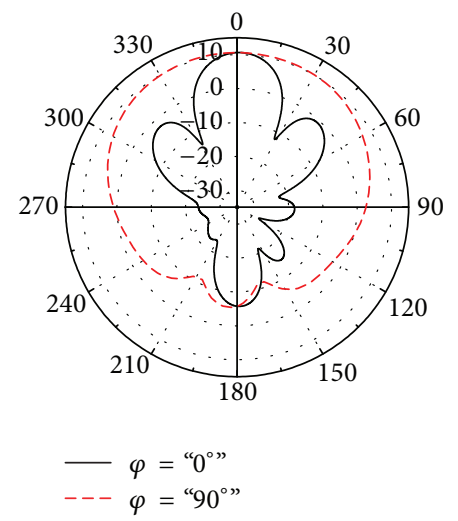

(a)

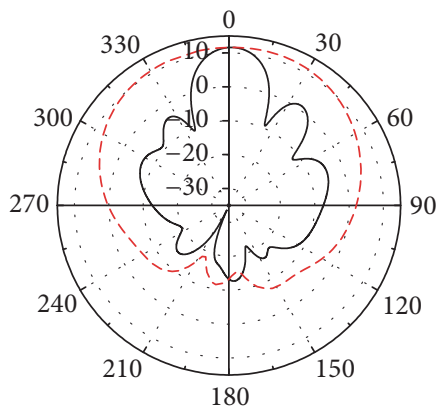

$\begin{aligned}-\varphi & =" 0 " ” \\ --\varphi & =" 90^{\circ} "\end{aligned}$

(b)

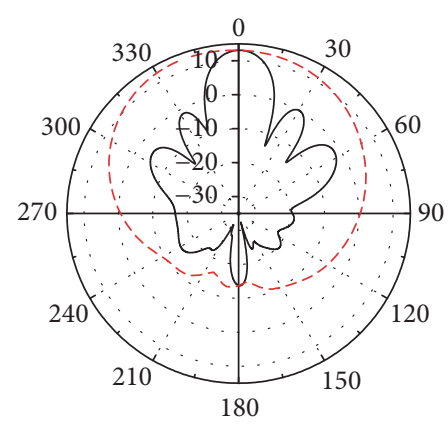

$\varphi=" 0^{\circ} "$

$--\varphi=" 90^{\circ} "$

(c)

FIGURE 11: Radiation pattern of the IMF-CBSA array without feeding network obtained in the simulation: (a) $18 \mathrm{GHz}$; (b) $22 \mathrm{GHz}$; (c) $26 \mathrm{GHz}$.

wide band and wide beam. The $45^{\circ}$ slant polarization is achieved by slanting the IMF-CBSA. The antenna array is simulated, fabricated, and tested. The measured VSWR $<2$ bandwidth is $55 \%(15.8-27.8 \mathrm{GHz})$ at the center frequency $21.8 \mathrm{GHz}$. The gain is larger than $12.2 \mathrm{~dB}$. It exhibits wide beam and slant linear polarization with small size of $68 \mathrm{~mm} \times$ $56 \mathrm{~mm} \times 14.5 \mathrm{~mm}$. The experimental results also demonstrate that the measured radiation patterns are coherent with the simulated radiation patterns.

\section{Competing Interests}

The authors declare that there is no conflict of interests regarding the publication of this paper. 


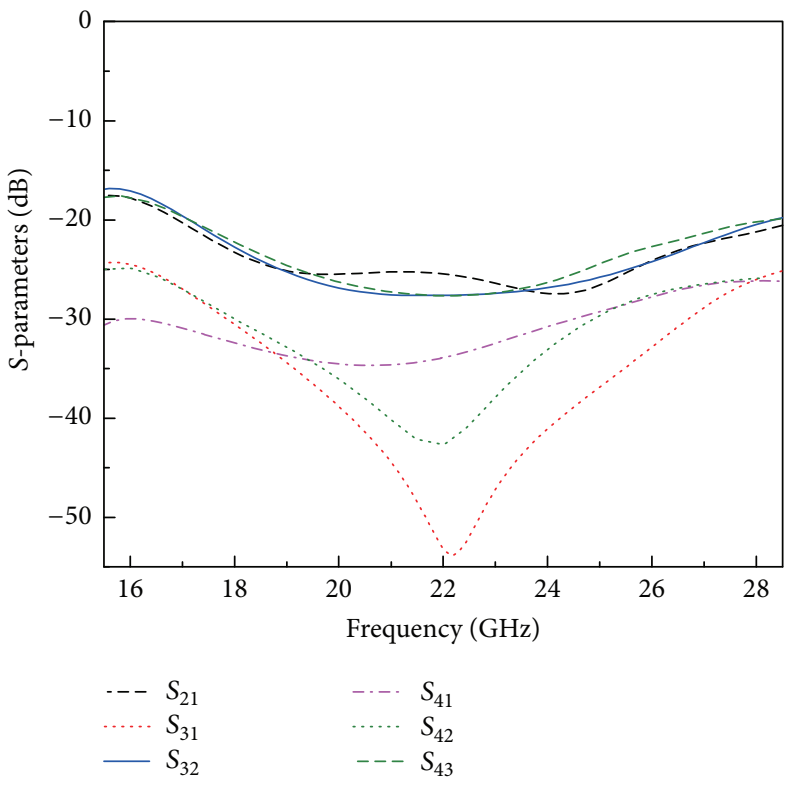

FIGURE 12: S-parameters of the IMF-CBSA array without feeding network.

\section{Acknowledgments}

This work was supported by the Program of 2014BAK12B03.

\section{References}

[1] H. G. Booker, "Slot aerials and their relation to complementary wire aerials (Babinet's principle)," Journal of the Institution of Electrical Engineers, Part IIIA: Radiolocation, vol. 93, no. 4, pp. 620-626, 1946.

[2] Y. Yoshimura, "A microstripline slot antenna (short papers)," IEEE Transactions on Microwave Theory and Techniques, vol. 20, no. 11, pp. 760-762, 1972.

[3] J. Galejs, "Admittance of a rectangular slot which is backed by a rectangular cavity," IEEE Transactions on Antennas and Propagation, vol. 11, no. 2, pp. 119-126, 1963.

[4] C. Cockrell, "The input admittance of the rectangular cavitybacked slot antenna," IEEE Transactions on Antennas and Propagation, vol. 24, no. 3, pp. 288-294, 1976.

[5] S. A. Long, "Experimental study of the impedance of cavitybacked slot antennas," IEEE Transactions on Antennas and Propagation, vol. 23, no. 1, pp. 1-7, 1975.

[6] Q. Zhang and Y. Lu, " $45^{\circ}$ Linearly polarized substrate integrated waveguide-fed slot array antennas," in Proceedings of the International Conference on Microwave and Millimeter Wave Technology (ICMMT '08), pp. 1214-1217, Nanjing, China, April 2008.

[7] Q. Li, Z. Shen, and P. T. Teo, "Microstrip-fed cavity-backed slot antennas," Microwave and Optical Technology Letters, vol. 33, no. 4, pp. 229-233, 2002.

[8] Q. Zhang and W. Wu, "Dual-band microstrip-fed cavity-backed slot array of circular polarization," in Proceedings of the IEEE Antennas and Propagation Society International Symposium (APSURSI '13), pp. 1720-1721, July 2013.

[9] Z. Chen and Z. Shen, "A compact cavity-backed endfire slot antenna," IEEE Antennas and Wireless Propagation Letters, vol. 13, pp. 281-284, 2014.
[10] J. Hirokawa, H. Arai, and N. Goto, "Cavity-backed wide slot antenna," IEE Proceedings H: Microwaves, Antennas and Propagation, vol. 136, no. 1, pp. 29-33, 1989.

[11] Q. Li and Z. Shen, "Inverted microstrip-fed cavity-backed slot antennas," IEEE Antennas and Wireless Propagation Letters, vol. 1, pp. 98-101, 2002.

[12] Q. Li and Z. Shen, "An inverted microstrip-fed cavity-backed slot antenna for circular polarization," IEEE Antennas and Wireless Propagation Letters, vol. 1, pp. 190-192, 2002.

[13] C. Jin, Z. Shen, R. Li, and A. Alphones, "Compact circularly polarized antenna based on quarter-mode substrate integrated waveguide sub-array," IEEE Transactions on Antennas and Propagation, vol. 62, no. 2, pp. 963-967, 2014.

[14] X. Quan, R. Li, Y. Fan, and D. E. Anagnostou, "Analysis and design of a $45^{\circ}$ slant-polarized omnidirectional antenna," IEEE Transactions on Antennas and Propagation, vol. 62, no. 1, pp. 8693, 2014

[15] R. F. Reinking, S. Y. Matrosov, R. A. Kropfli, and B. W. Bartram, "Evaluation of a 45。 slant quasi-linear radar polarization state for distinguishing drizzle droplets, pristine ice crystals, and less regular ice particles," Journal of Atmospheric and Oceanic Technology, vol. 19, no. 3, pp. 296-321, 2002.

[16] M. Kaboli, S. A. Mirtaheri, and M. S. Abrishamian, "Highisolation X-Polar antenna," IEEE Antennas and Wireless Propagation Letters, vol. 9, pp. 401-404, 2010.

[17] M. Amin, R. Cahill, and V. Fusco, "Single feed low profile omnidirectional antenna with slant $45^{\circ}$ linear polarization," IEEE Transactions on Antennas and Propagation, vol. 55, no. 11, pp. 3087-3090, 2007. 


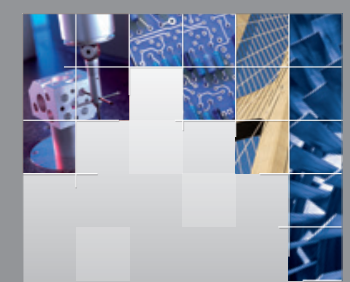

\section{Enfincering}
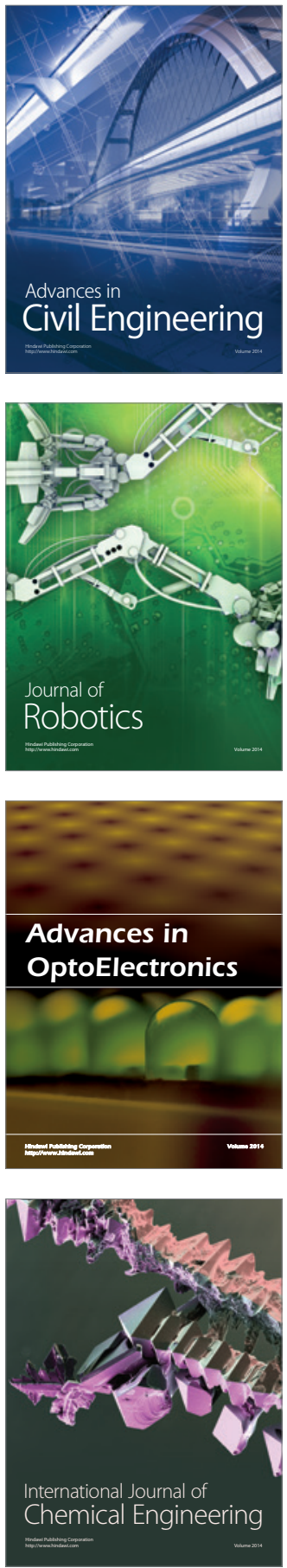

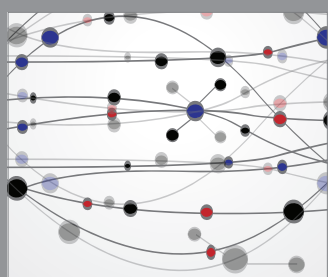

The Scientific World Journal

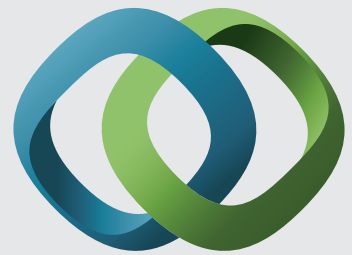

\section{Hindawi}

Submit your manuscripts at

http://www.hindawi.com
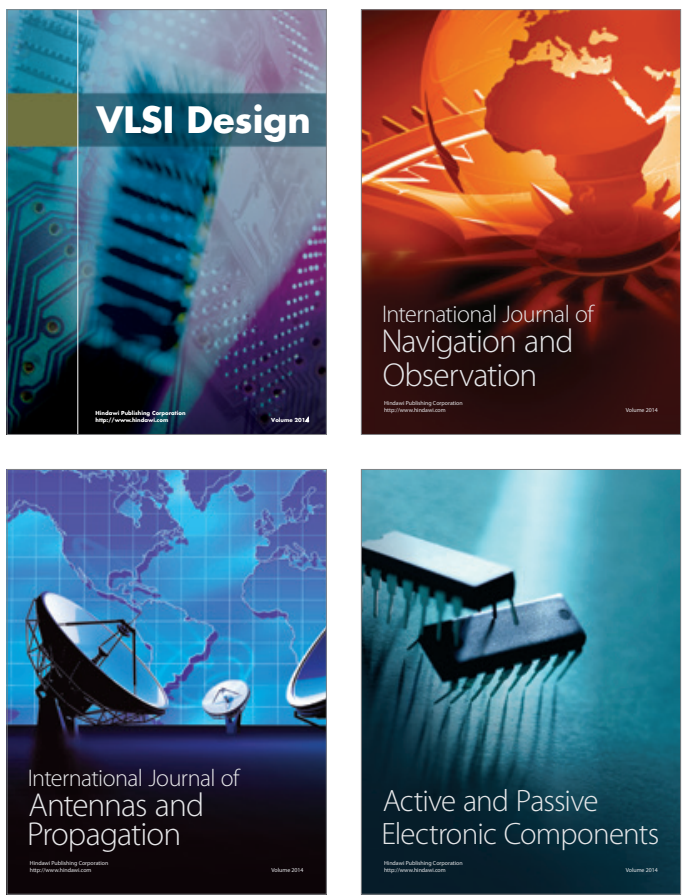
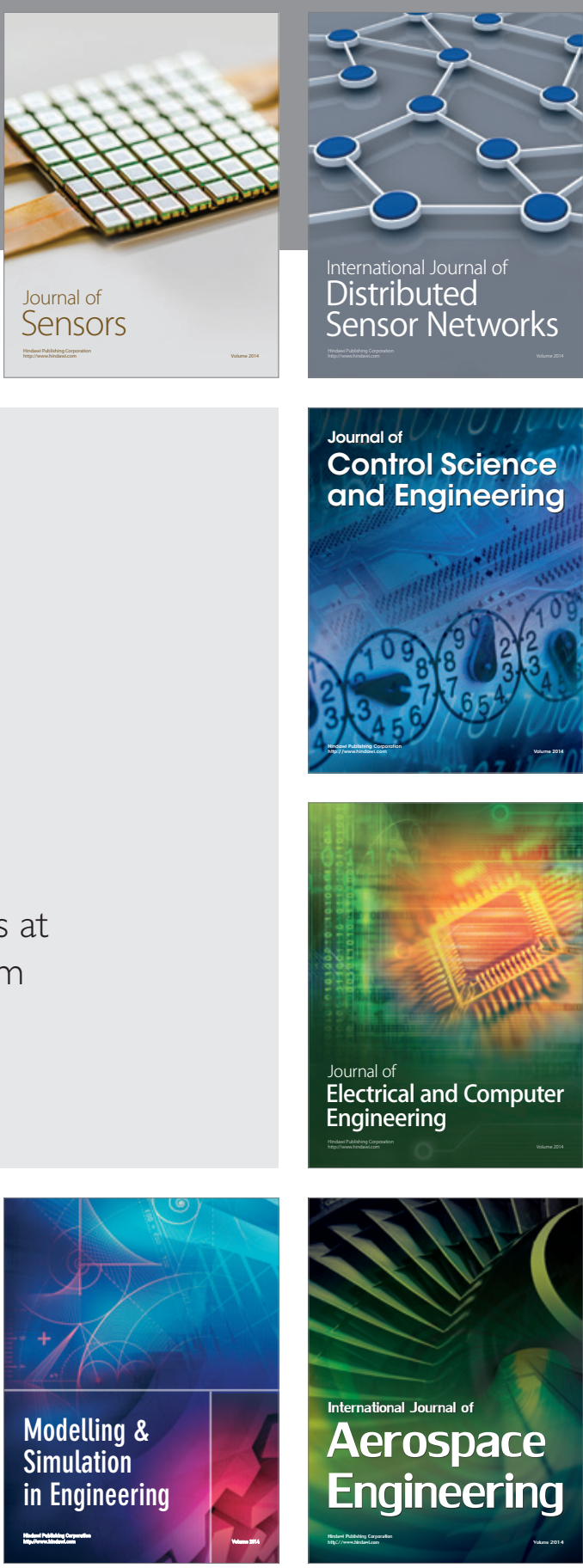

International Journal of

Distributed

Sensor Networks

Journal of

Control Science

and Engineering
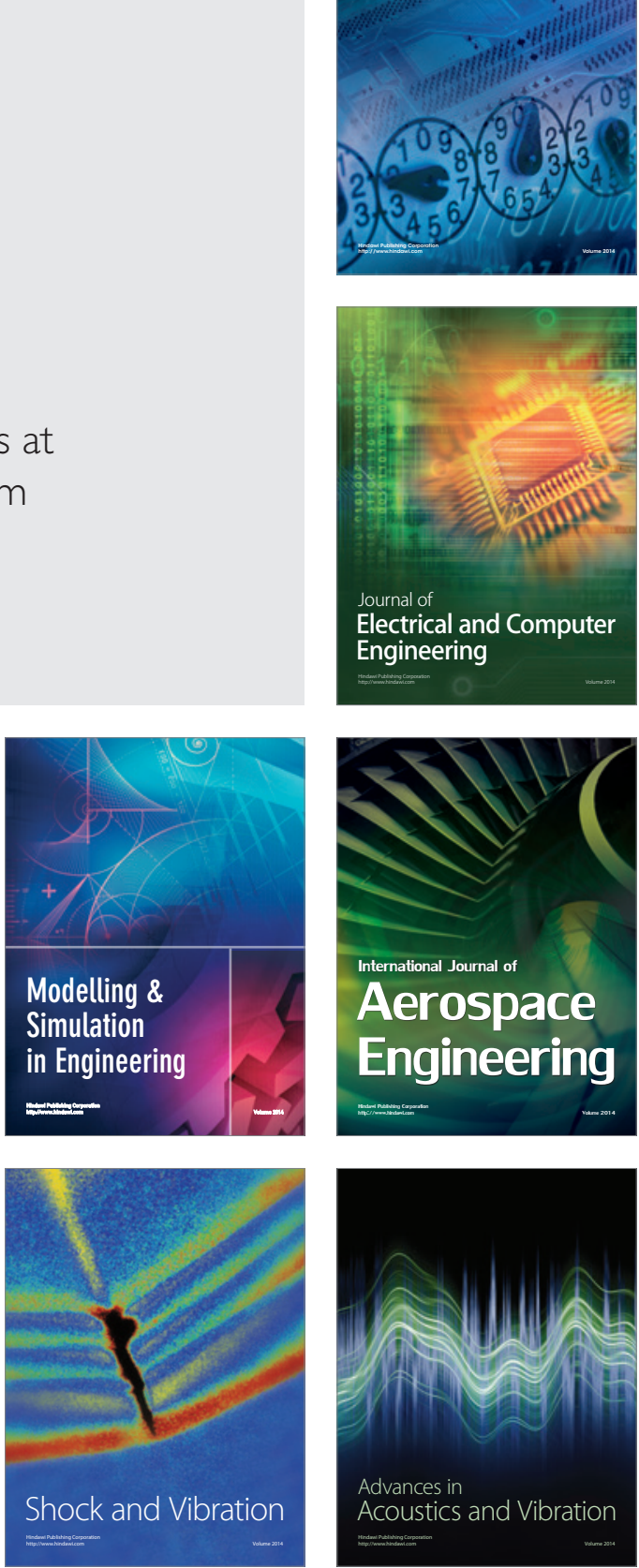